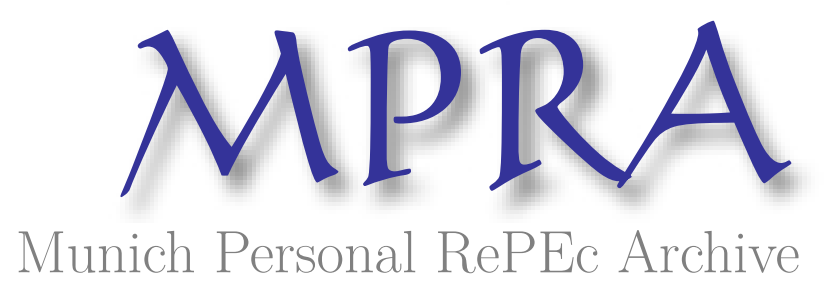

\title{
The potential use of derivatives to manage the price risk of seafood markets: the case of sole and cuttlefish in France
}

Bégué-Turon, Jean-Loïc and Perraudeau, Yves and Rautureau, Nicolas

4 October 2006

Online at https://mpra.ub.uni-muenchen.de/841/

MPRA Paper No. 841, posted 15 Nov 2006 UTC 


\title{
LEN \\ Laboratoire d'Economie de Nantes
}

Cahier de Recherche

\section{The potential use of derivatives to manage the price risk of seafood markets: the case of sole and cuttlefish in France}

\author{
Jean-Loïc Bégué-Turon (Commorisk) \\ Yves Perraudeau (LEN) \\ Nicolas Rautureau (LEN)
}

JEL Classification Codes: G00, O13, Q14, Q22

Key words: Cuttlefish, Derivative instruments, Price risk management, Sole

Université de Nantes

Faculté des Sciences Economiques et de Gestion 


\section{The potential use of derivatives}

to manage the price risk of seafood markets:

the case of sole and cuttlefish in France

October 2006

\section{Jean-Loïc Bégué-Turon}

Commorisk

19, boulevard Malesherbes. 75008 Paris - France

Tel: (33) 155273977 - Fax: (33) 155273707

info@commorisk.com

\section{Yves Perraudeau}

Université de Nantes, LEN

UFR des Sciences Economiques et de Gestion - Chemin de la Censive du Tertre BP 52231 - 44322 Nantes Cedex 3 - France

Tel: (33) 240141663 - Fax: (33) 240141650

yves.perraudeau@univ-nantes.fr

\section{Nicolas Rautureau}

Université de Nantes, LEN

UFR des Sciences Economiques et de Gestion - Chemin de la Censive du Tertre BP 52231 - 44322 Nantes Cedex 3 - France

Tel: (33) 240141653 - Fax: (33) 240141650

nicolas.rautureau@univ-nantes.fr 


\begin{abstract}
Taking into consideration the changes in the rules for the price support for agricultural and sea products, it seems appropriate to find out what other means could be used to cover the price risk in order to protect the commercial margin of these sectors of activity. The use of derivatives tools helps achieve this objective. We first emphasize the interest of such a study for fresh seafood markets and make a brief presentation of the various tools available to facilitate the understanding of future choices. Then we conduct a statistical analysis concerning the common sole and cuttlefish French markets which shows a good correlation level between sizes, presentations, qualities and the possibility to launch indices by species and OTC optional transactions on them. The last section brings into perspective the results and points out the various steps to take to make it functional.
\end{abstract}

\title{
Acknowledgements
}

This work has received the financial support of OFIMER and IFOP and was also supported by the FEDOPA, DPMA, CNPMEM and FPAP. We also thank the participants at the IIFET 2006 Conference at Portsmouth, Patrice Guillotreau, Frédéric Gonzales and Sophie Pardo. 


\section{Introduction}

As in a number of other sectors, we are observing a growing internationalization in the seafood market which had been operating within the guidelines of the GATT agreements but today is under the WTO. So, the opening of the seafood market to the world market should mean a liberalization of prices leading to a decrease in present base price levels (such as wheat) but equally, as was mentioned at the time of the last WTO meeting in Hong Kong, a disappearance of exportation assistance, and even assistance for price support (such as withdrawal price levels for the fishing industry). In addition, certain species are already subject to large price variations and to an established seasonality. In this context, it appears essential to be prepared to manage price risk as soon as there are weak profit margins for the operators and/or high price volatility.

Starting from these observations, one can imagine the use of derivative tools to cover the risk of price fluctuations to guarantee a part of the producer's income. It appears that this financial practice, that has already been put into place in the agricultural sector for certain crops, has been a subject of discussion over the past several years in the profession $^{1}$ and particularly, within the framework of the Coopération Maritime, a French professional organization. Hence, the work of Gourlaouen et al. (2003) concerning the hedging strategies against the oil price fluctuations in the fishing sector, has served as a basis for the creation of the Funds for Prevention against Fishing Risks $(\text { FPAP })^{2}$. Moreover, futures markets on frozen shrimp have been launched by the Minneapolis Grain Exchange (MGE) and the Kansai Commodities Exchange. 
This paper results from the same logic, which is to search for derivative tools for seafood products in order to maintain the margins of the actors in this industry. It rests on the project of Bégué-Turon, Perraudeau and Rautureau (2006) concerning 12 species which together have an important place in French fishing activity. Our contribution comes from the absence, or the small amount, of studies on this theme applied to fresh seafood products, which is not the case for the literature on futures markets (see Bergfjord (2006) for a recent presentation of the literature on this subject). We also stress that a discussion on derivatives should not be limited to futures markets. Furthermore, we use monthly data of 47 French auctions from 1994 to 2005 to build global price indices for the cuttlefish and the sole markets ${ }^{3}$. The sole is the first landed species in value in France in 2005 with 72,144 million euros and the cuttlefish the 8th with 21,713 million euros (89,754 and 27,013 million dollars respectively).

Firstly, we underline the interest of such an approach taking into account the development of business regulations, the use of derivative tools in other sectors and the specific elements of the seafood industry suitable or not to the application of these instruments. Secondly, these tools will be generally presented in order to better understand the subsequent choices. Thirdly, the examples of the sole and cuttlefish are presented to illustrate the empirical approach. This work is based on the monthly data furnished by OFIMER during the period 1994/01 - 2005/12 relative to the size, presentation, quality (SPQ henceforth) and auction markets. The statistical study is mainly interested in questions of correlation to find a unique representative price and of the evolution of fishing volumes. The results are analyzed in a fourth part from a 
perspective of a possible launching of a derivatives market for these species. The conclusion puts into perspective the elements advanced and underlines the stages that remain to be gone through to make such an approach work.

\section{General interest of the approach}

Is it a suitable moment to consider the question of the management of price risk?

Even if this study is conducted in a French context, just as the European agricultural forward markets were first launched by France, the risk management approach is perfectly in keeping with European logic. The problems of price risk management will be the same for all the different European fishing sectors as soon as the opening of markets is made clearer or the regulation of the current system of price support (withdrawal, orientation price) develops toward a greater disengagement by public authorities.

Concerning maritime fishing, the European Union benefits presently from a Common Fisheries Policy (CFP) established in 1983, as a result of the Treaty of Rome and the regulations of 1970, which discards the basis of this sectoral policy. The CFP is greatly inspired by the Common Agricultural Policy, both in its financing and in its policy for the regulation of markets and prices. The replacing of the Financial Instrument for Fisheries Guidance (FIFG) by the European Fisheries Fund (EFF) in the framework of the structural funds reform 2007-2013 and the current review of the common 
organisation of the market $(\mathrm{COM})$ regulations, under the liberal pressure of certain community members who oppose all public intervention, confirms the withdrawal (relative) of the EU from direct assistance policies in the sector. All these reforms are in accordance with the conclusions of the last WTO meeting in Hong Kong which stipulated that by 2012 there should be an end to (or sharp decrease in) assistance to agricultural prices in the developed countries which would also concern sea products ${ }^{4}$. For these reasons, a single market approach, by raising the volumes treated and number of actors concerned, would be a positive element concerning the feasibility of resorting to derivative instruments. The European dimension could be the optimal size for the feasibility of such a practice.

Do encouraging elements or brakes exist for these tools?

Some obstacles are present particularly for fresh fish, as a harvesting activity, due to unpredictable volumes and the existence of many different species and differences (norms for the size, quality and presentation). Moreover, a lack of market liquidity could occur, which can result from an insufficient number of operators and/or transactions, even if derivatives instruments are open to all the actors in the industry, (producer, transformers, industrialist, distributor ...). Lastly, in the case of seafood products, the fact that derivative products for the sector do not yet exist will require the creation of a recognized index beforehand (kind of price reference for all auction markets). We bring a response to this latter point in the second part of this paper. 
We can also mention two other problems met for any launch of new by-products. First, the risk of operators' diverging interests possibly leading certain actors to hinder the creation of a derivatives market, like the soy bean industry in France. Second, the difficulty to understand hedging systems could lead to the mistrust of the actors and to their non-involvement. These techniques are complex and require pedagogical training (see Dinwoodie and Morris. 2003 for example).

These numerous difficulties should be refined. In effect, these problems are found in many sectors including certain that have already adopted these hedging techniques. Moreover, sea fishing today holds certain elements that are in its favour for derivative instruments to function well. First, official quotation of seafood products is carried out daily by auction. This structure assures the first sales of the numerous products unloaded (around 2/3 the value unloaded in fresh fish, more than half of the total value unloaded). Second, the counterpart risk in the transaction is increasingly weak since there has been developed these last years on the Atlantic coast and in Brittany, mutual guaranty funds for the fishing trade which assures that fishermen will be paid for their sales at auction. Lastly, there already exists a prevention fund to bring a collective rather than an individual answer to fishing risks, the FPAP. It encompasses not only fuel but also "the closing out of quotas or the substantial reduction of fishing possibilities" and "the relative market risk", 
Beyond these answers to the two prior questions, looking at historical or recent observations, it seems clearly that the success of the creation of a derivatives market depends largely on the real volition of all the industry actors to adopt these hedging tools. Concerning this subject, we can observe almost all of the French fishing professionals rapidly signing up to enter into the FPAP for the oil hedging, with 2000 registration requests for membership at the beginning of December, 2004, representing 2400 ships. One must not forget either the evolution of business behaviour with the development of the Pan European Fish Auctions ${ }^{6}$ which means the introduction of an "immaterial" dimension into the reasoning of industry professionals.

\section{A brief introduction to derivative instruments ${ }^{7}$}

Transactions of raw materials as well as seafood products are carried out in a traditional way in an Over the Counter (OTC) market. That is to say the two contracting parties know each other and are both responsible for the proper execution of the contract. Moreover, this market is called physical or "cash" contrary to derivative markets because they are based on deliverable merchandise. When two parties negotiate a transaction, they have to agree on a number of points such as the quality, method and place of delivery, as well as the price, payment conditions ... For fishing, one can talk about size, quality, presentation, delivery place, availability or price.

Concerning raw materials in the short term, the transactions are almost always done at a fixed price. The merchandise is sold "spot", that is to say "right away". This is 
obviously often the case for products which can't be conserved very long because they are perishable, like fresh fish. It is also possible that the price of the merchandise may have been negotiated long before its delivery. One speaks then of a forward transaction as opposed to a spot transaction.

To manage the price risk of a future transaction it is also possible to resort to futures markets. Futures markets as opposed to OTC markets are said to be "organized" or "regulated". In the shipping industry for example, Imarex has opened this kind of market for freight derivatives on the $2^{\text {nd }}$ November of 2001. Their organization appears at several levels. First, in order to increase liquidity, an index or financial contract is created, the most representative of the underlying item as possible. The futures market contract is about this index. In the next section, one endeavours to create a reference to which the entire market can be identified. Futures markets are considered as "financial" or "paper" markets in the sense that, except in exceptional cases, the actual delivery of the instruments traded doesn't take place. Instead of this there are only payments between bank accounts in connection with the covered underlying asset and price fluctuations.

Two futures markets on frozen white shrimp and on black tiger shrimp have also been launched by the Minneapolis Grain Exchange (MGE) respectively in July 12, 1993 and in November 14, 1994. But they are dormant contracts since January 10, 2002. Martinez-Garmendia and Anderson (1999) explain the lack of liquidity of these 
contracts by the modest hedging effectiveness of MGE contracts (see also Sanders and Manfredo. 2002). Maynard, Hancock and Hoagland (2001) obtain the same result and show that the basis risk was high relative to the price risk, which stresses the importance of the correlation between the futures and the wholesale cash markets. Another difficulty was the context of the multiple deliverable category character (MartinezGarmendia and Anderson. 1999; Pennings and Leuthold. 2001; Pennings. 2002). Sanders and Pennings (1999) also stress difficulties of cash-futures arbitrages, due to a hard cash market access for new economic agents, problems of hard third party grades and standards acceptance and the under-estimated costs of hedging programs, which include particularly training and assistance given to the operators and accounting and risk management practices. Sanders and Manfredo (2002) and Dinwoodie and Morris (2003) also establish a link between technical education and derivatives market liquidity. Nowadays, the Kansai Commodities Exchange in Japan has the only active frozen shrimp futures market in the world ${ }^{8}$. But other projects exist. Hence Bergfjord (2006) offers coverage of existing projects in Norway to launch futures markets for Salmon.

In fact, in order to increase liquidity, contrary to OTC markets, one seeks first to standardize the contract characteristics: fixed delivery dates, ticks, etc. Second, in these markets, the quotations are officially carried out at the open outcry exchange or at an electronic market. All transactions are registered and known by the other operators. Third, the operation on a futures market involves an entire series of controls and the existence of a clearing house to eliminate the counterparty risk. The clearing house has 
to settle trades and to regulate delivery. Hence, after an initial payment by the seller and the buyer, which is the deposit and is usually between 5 and $10 \%$ of the contract value, all profits and losses are credited or debited from the counterparties' clearing house on a daily basis. Contrary to a market by mutual agreement, an operator in the futures market has as counterparty, the market itself, which is precisely the clearing house.

For the most important use of futures contracts, that is hedging, the purpose of these markets is to offset spot price fluctuations of the underlying asset. A hedge is established by taking an opposite position in the futures market than in the physical or cash market. Futures markets present numerous advantages but they cannot function conveniently unless a certain number of conditions are fulfilled. One of the main problems comes from the fact that application of administrative regulations and monitoring can be very costly.

Optional products can also be negotiated on OTC markets or on regulated markets. From the sixteenth century, certain Dutch or Genoese merchant bankers resorted to option instruments to protect themselves against currency risks and the fluctuation in price of certain raw materials, like options on Tulip bulbs in Amsterdam around 1600s (Reuters 2000). Options owe their origin to a strong degree of aversion to the lack of earning or the regret of a subsequent favourable price evolution. Against the payment of a premium, the holder of the option has the right, but not the obligation, to buy or to sell 
a product at a definite price, over a given period of time. On the other hand, the seller of the option has the obligation to follow the decision of the buyer ${ }^{9}$.

Hybrid market organizations also exist as is the case for shipping derivatives. This sector is interesting for the fresh seafood market because it shares some similar features with an underlying asset non-storable (the shipping service) and transactions costs that are higher in the physical market than in the financial market (Kavussanos and Visvikis. 2002). In the mid-1980s the Baltic International Freight Futures Exchange (BIFFEX) enabled the trading of futures contracts and options based on the original Baltic Freight Index (BFI). The BFI launched January $4^{\text {th }}, 1985$, was a composite index and initially consisted of 13 voyage routes of dry cargo. Contracts ceased to be traded in April 2002 on this regulated exchange due to lack of liquidity. One of the main problems was an insufficient correlation between BFI evolution and the sectoral dynamics of its components (Kavussanos and Nomikos. 2000a, b; Haigh, Nomikos and Bessler. 2004). However, Haigh (2000) observes that this result is not driven by a lack of efficiency but more by the increase of the freight forward market. Furthermore, Haigh and Holt (1999) regret that this freight futures market was underutilized for reducing price uncertainty. But the positive aspect is that, from this date, the BFI has won acceptance as a reliable indicator of the physical market (Drewry 2004).

Nowadays, the Baltic Exchange issues indices for bulk carriers and tankers. The current derivatives are Forward Freight Agreements (FFA) which work with any routes 
included in the Baltic Exchange indices ${ }^{10}$. Therefore, these latter connect derivatives markets to physical markets. At the outset FFA trading was an OTC market ${ }^{11}$. FFA are made on a principal-to-principal basis where the broker acts as intermediary only. A physical delivery of the indices doesn't take place from operations on indices, but rather there is a cash flow at the delivery date. Swaps between a variable rate (one of the indices) and a negotiated fixed rate constitute the majority of the deals but option agreements also exist. However, the Norwegian Futures and Options Clearinghouse (NOS), NYMEX and the London-based LCH.Clearnet also propose clearing activity for these agreements ${ }^{12}$. Activity on these indices can therefore be OTC products which depend on prices officially published by an organization, the Baltic Exchange, and products traded on IMAREX, a regulated market established in 2000. The higher activity on FFAs than on BIFFEX can be explained by a greater flexibility, lower transaction costs, the creation of sector-based indices in place of a unique composite index and the international environment among others. Moreover, some studies show that for some routes, the FFA prices are unbiased predictors of spot prices (see Kavussanos, Visvikis and Menachof. 2004 for example) $)^{13}$.

\section{Sole and Cuttlefish: From proven theory to practical advice}

\section{Methodology}

At this stage, we have seen the interest of the approach and the different possible instruments for price risk management. In this section we conduct a statistical analysis of the French spot market for sole and cuttlefish to address mainly the questions of 
correlation between the different spot prices and of liquidity, which are the first elements to consider before launching a derivative market. Indeed, it is difficult to have a liquid options market if the underlying spot market is not one. The fresh seafood markets have two difficulties from this point of view. First the production of fish depends on the Size (T), the Presentation of the product (P), and the Quality (Q), as well as the concerned fishing port. Second, landed quantities are uncertain and variable.

We use monthly data furnished by OFIMER during the period 01/1994 - 12/2005 relative to the size, presentation, quality and auctions markets to conduct the statistical analysis. For sole, there are 49,523 monthly observations over the period, with 5 criteria for size, 7 for presentation and 4 for quality. Hence, for each month and for each auction market, we have the possibility to observe 140 different prices. For cuttlefish, there are 22,769 monthly observations over the period, with 5 criteria for size, 10 for presentation and 4 for quality, which gives 200 possible different price series for each month and each auction market. During the period of 12 years, there were 47 auctions recorded in the database where there were sole and cuttlefish sold at least during one month. In this case, it could be very difficult to have one representative price for sole.

We begin by building the individual price series for each auction market and for each SPQ combination. Then from these price series representing each SPQ combination per auction, we construct aggregate indices, i.e., time series for each SPQ combination at a national level ${ }^{14}$. The importance of each auction market in the index then depends every 
month, on the quantity fished locally for the considered SPQ combination, referred to the total fished quantities for the entire territory for the same month and for the same SPQ combination ${ }^{15}$. There are two consequences of using this methodology. First, the importance of each auction market is different for the various SPQ combinations. Second, the importance of each auction market can vary every month ${ }^{16}$.

Then we select an index covering the highest number of criteria possible concerning Size, Presentation and Quality, in order to obtain a price indicator representing significant fished quantities, thus enabling us to ensure the representativity of the spot market and the future liquidity of potential derivative instruments. The ultimate limit of this "size race" is the level of correlation observed between SPQ criteria selected in the aggregate index. In fact, the evolution of the aggregate index should, to be efficient, be in phase with the variations of each of its components (the national index of the SPQ combinations). We end by the analysis of the global index in terms of dynamics of the volumes and monthly volatility. All calculations in this study are performed with the Gauss software.

\section{The Sole study}

Table 1 shows that the market for Sole is of average concentration, with the 12 first auctions selling $76.73 \%$ of the national quantities. Boulogne, Dunkerque, Noirmoutier, Arcachon, and Les Sables d'Olonne were the main fishing ports in 2004. 
[ Insert Table 1]

Table 2 shows that sizes 4 and 5 are the largest fished sizes with respectively $30.17 \%$ and $23.58 \%$ of the volumes. The correlation between sizes is very high overall, but not the correlation between end range sizes, i.e., 1 and 5 and 2 and 5 (respective sizes, 0.47 and 0.58 ). The correlation matrix shows that sub-indexes by size might also be studied (Table 3).

[ Insert Table 2 ]

\section{[ Insert Table 3 ]}

The relative stability and low level of price for size 5 are demonstrated in figure 1, even if seasonal trends in the short term are close. The trends for sizes 1, 2, and 3 are, on the contrary, very similar. The lowest price level for size 5 is illustrated by a mode for the price level distribution between 6 and 7 euros per kilo as contrasted with the higher levels at 10 euros per kilo for the other sizes. Likewise, the relative price stability for size 5 is shown by amplitude that is the weakest of the distributions (concentration between 4 and 11 euros per kilo for size 5 versus 5 to 20 euros per kilo for size 1 for instance).

\section{[ Insert Figure 1 ]}

Two presentations ("whole" and "gutted") represent the total fished quantity, namely the "gutted" with $57.01 \%$ of the total quantity and "whole" with $42.99 \%$. Their correlation is very high (0.86) even if the first one is slightly more volatile (figure 2). Moreover, prices are slightly higher for the presentation "gutted" as the mode of 
distribution of price levels around 12 euros per kilo versus 10 euros per kilo for the presentation "whole" shows. Thus the aggregation of these criteria does not present a problem.

\section{[ Insert Figure 2 ]}

The quality " $\mathrm{A}$ " is the most represented with $60.33 \%$ of the production, followed by highest quality "E" with $38.43 \%$, and then quality "B" with $1.24 \%$. Quality "E" shows a slightly higher price than quality "A" but the correlation between the two criteria remains at a very high level of 0.94 which allows the aggregation of these two criteria in the same global index (figure 3).

\section{[ Insert Figure 3 ]}

As a consequence, we choose a global index as the index of reference, even if size subindexes may also be relevant. This index regroups sizes 10, 20, 30, 40 and 50, the presentations "whole" and "gutted" and the qualities "E", "A", "B", and "C". The fished volumes follow a seasonal dynamic, without any apparent problem of a diminishing tendency (figure 4).

\section{[ Insert Figure 4 ]}

The price trend is slightly positive in the long run (figure 5). The level of the monthly volatility is computed according to:

$$
\sigma^{2}=\sqrt{\frac{\sum_{i=2}^{T}\left(\ln \left(\frac{y_{t}}{y_{t-1}}\right)\right)^{2}}{T-1}}-\sqrt{\frac{\left(\sum_{i=2}^{T} \ln \left(\frac{y_{t}}{y_{t-1}}\right)\right)^{2}}{T^{*}(T-1)}}
$$


where $T$ is the number of observations and $y_{t}$ the price level of the index at date $t$. The level of the monthly volatility for Sole is reasonable with a value of $11.84 \%$. The prices are centered around an average of 11 euros per kilo for the period. The price variations between each size index and the global index can be significant. However, they remain below 75 cents per euro as a weighted average for the most represented size (size 4). Moreover, these substantial variations need to be examined keeping in mind the high price of Sole.

\section{[ Insert Figure 5 ]}

The Cuttlefish study

The Cuttlefish market is a market of average concentration, with the first ten fish auctions producing $76.38 \%$ of the total volume. Boulogne-sur-Mer, Cherbourg, Port en Bessin and Le Guilvinec are the main fish auctions in 2004 (table 4).

[ Insert Table 4 ]

Three sizes are significant during the period, with $56.31 \%$ of the production for size 10 , $25.24 \%$ for size 30 and $16.06 \%$ for size 20 (table 5). Their correlation is high, even if the ratio obtained for the two first sizes is only $0.64 \%$. Thus, the size sub-indices might be studied (table 6 and figure 6 ).

[ Insert Table 5 ]

[ Insert Table 6 ] 


\section{[ Insert Figure 6 ]}

Taking into account the very high concentration of data concerning the criteria "whole" with $99.88 \%$ of the recorded observations, we don't perform a correlation analysis between the various presentations of the cuttlefish.

The quality " $\mathrm{A}$ " is the most represented with $79.05 \%$ of the production, followed by highest quality "E" with $20.60 \%$. The correlation between these two qualities is high, with a value of 0.81 (figure 7). Moreover, their volatility is close, even if quality "A" seems to be more stable as shown by its highest price variations concentration around zero. To aggregate these criteria in one index is therefore acceptable.

\section{[ Insert Figure 7 ]}

Consequently, a global index will be used as the reference index, even if size subindices may be considered. This index regroups the sizes 10, 20, 30 and 40, the presentation "whole" and the qualities "E", "A", "B" and "C". The fished volumes follow a strong seasonal dynamic without any apparent structural problem (figure 8).

\section{[ Insert Figure 8 ]}

The price trend is rather stable in the long run, with one significant peak in 2005 . The level of the monthly volatility observed is reasonable with a value of $12.37 \%$ (figure 9). Prices are concentrated between 1.80 and 2 euros per kilo during the period. We can also notice a slight asymmetry of the price levels distribution with a few values above 2.80 euros per kilo. 


\section{[ Insert Figure 9 ]}

\section{From analysing the results to setting up the tools}

The statistical approach shows that it can be possible to build a representative index for the markets of the sole and the cuttlefish, which constitutes the first step before the launching of derivative instruments. But, taking into consideration the selected seafood product characteristics, what would be the most relevant tool?

In order to supply a strong basis for the development of a derivative market, using examples from agriculture, the analysis of Heifner (2004) and our results, table 7 indicates a list of 10 elements required for setting up the market. Bergfjord (2006) for futures markets only divide "success factors" into four groups (related to underlying commodity market, to actual and other futures contracts and to exchange and users). But no major differences appear. As we can see, the necessary conditions for the success in setting up derivative markets are not easy to find. These can differ according to the particularities of each market.

To summarize, futures markets do not match the needs of the fresh seafood products sector. Futures markets find their reason for development in a form of contractualization of recurring flow: the physical flow is contractualized and at the same time there is a price risk management operation on the paper market. Consequently, as a harvesting 
activity, the fresh seafood sector doesn't seem entirely adapted to futures. Moreover, futures markets - which have operating costs that are quite high - are profitable only if the operators and transacted volumes are substantial.

It is better to go towards an OTC market with operations on indices and towards insurance mechanisms like options rather than towards forward instruments. Index markets seem more appropriate than regulated markets due to their fewer constraints especially concerning financial cost and administration. And in their application, there is not a major difference in terms of price risk management.

In the "shipping" or sea freight market, as we saw, the experience of setting up a real futures market with the BIFFEX did not last long, even if there is today a regulated market for freight derivatives in Norway with Imarex. The BIFFEX closed down at an early stage and has now been replaced by an index market. These quotations are performed by the Baltic exchange. These indices are used for a whole series of transactions and instruments.

Moreover, the choice of an index market does not exclude other choices and it leaves open the question of derivative tools (options or swaps). It is even quite logical to have several instruments offered to the operators of the sector. In the agriculture sector, the operators can utilise a wide range of products to cover their risks, and this can be 
observed all over the world. Other possible solutions are classic insurance such as revenue insurance for the producer, risks mutualisation and State assistance to the sector with subsidies for production, sales or exports.

\section{Conclusion}

The change in the social-economic context in both Europe and the rest of the world towards deregulation and a growing liberalisation of prices should justify the setting up of derivative instruments, like for agricultural products, for example. To think about such a development for the seafood product sector is totally legitimate today.

The fact that seafood products are fresh and perishable might be an obstacle to derivative instruments, particularly for futures or forward markets. However, optional tools and OTC markets seem better adapted. This sector has other advantages such as price transparency obtained via the auction markets and the auction markets electronic network in France which gathers sales data very quickly. Moreover this study, which has been done for the French area, could be extended to the entire European zone bringing the advantage of improving the liquidity of the markets and increasing the interest for all the operators.

However, a certain number of obstacles could block the process even if theory shows the feasibility of creating such an index. We take note of the following points. First, 
there must be total commitment from the operators of the sector. In some agricultural markets, some influential operators have caused futures contracts to fail because price transparency could reduce their influence on the market. But mostly the buyers are product transformers and need a regular flow of goods without price risk, and that can explain that they are interested by such tools. Their commitment is crucial.

Second, there must be a sufficient transaction volume. Intermediary actors need to feel involved in the project for that to happen. It is necessary to find a way to incite market actors to get involved. It is also desirable that some operators and some "institutional actors" may actively participate in the market.

Third, it seems obvious that guiding actors are needed for this project. Their role will be to ensure that operators are safely covered by buying and selling indices. Lastly, the training and assistance given to the operators who wish to be active are compulsory conditions for the success of such a project. To be aware of the existence of a risk is not sufficient, the operators must also understand the tools, the techniques and the mechanisms (Sanders and Pennings. 1999; Sanders and Manfredo. 2002 ; Dinwoodie and Morris .2003).

Our results suggest that the use of derivative markets to manage price risk of seafood markets, as well as the reflexion on this subject, should not be limited to futures market, 
as shown by the developments for the maritime freight. Moreover, after a first encouraging conclusion about the theoretical feasibility of the creation of a market of derivative instruments for fresh seafood market in France, it could be interesting to analyze more in-depth indices built with higher frequency data, due to the importance of contract design. Finally, it is important to underline the precautions to be taken in the manner of setting up such a project, in particular in terms of animation of the market and the assistance to the operators. 


\section{References}

Anderson James L. and J. Martinez-Garmendia. 2003. Price Discovery. The International SeaFood Trade. J.L Anderson ed., Woodhead Publishing Limited. United Kingdom

Bégué-Turon J-L., Perraudeau Y. and N. Rautureau. 2006, Gestion du risque de prix des produits de la mer : faisabilité théorique d'un marché dérivé. Rapport. LEN. Université de Nantes. 393p.

Bergfjord O.J. 2006. Is there a future for salmon futures? An analysis of the prospects of a potential futures market for salmon. IIFET 2006 Conference. Portsmouth

Clark E., Lesourd J-B. and R. Thieblemont. 2001. International Commodity Trading: Physical and Derivative Markets. John Wiley \& Sons. Chichester

Dinwoodie J. and J. Morris. 2003. Tanker forward freight agreements: the future for freight futures? Maritime Policy and Management. 30(1): 45-58 
Drewry. 2004. Forward Freight Agreements (FFA) and Shipping Derivatives. Report of Drewry Shipping Consultants Ltd

Gourlaouen J.P., Langlois A., Merabet P. and E. Evin. 2003. Stratégies de couverture contre les fluctuations du carburant pêche. Rapport. LEN-Corrail. Université de Nantes. 21p.

Haigh M.S. 2000. Cointegration, unbiased expectations, and forecasting in the BIFFEX freight futures market. Journal of Futures Markets. 20(6): 545-71

Haigh M.S. and M.T. Holt. 1999. Volatility spillovers between foreign exchange, commodity and freight futures prices: implications for hedging strategies. Faculty Paper 99-5. Dep. Of Agr. Econ. Texas A\&M University

Haigh M.S., Nomikos N.K. and D.A. Bessler. 2004. Integration and causality in international freight markets: modeling with error correction and directed acyclic graphs. Southern Economic Journal. 71(1): 145-62 
Heifner R. 2004. Potential for Futures Trading in Catfish and Salmon. Department of Agricultural Economics report. Mississippi State University

Hull J.C. 2005. Options, Futures And Other Derivatives. Sixth Edition. Prentice Hall

Kavussanos M.G. and N.K. Nomikos. 2000a. Constant vs. time-varying hedge ratios and hedging efficiency in the BIFFEX market. Transportation Research Part E. 36: $229-48$

Kavussanos M.G. and N.K. Nomikos. 2000b. Futures hedging when the structure of the underlying asset changes: the case of the BIFFEX contract. Journal of Futures Markets. 20(8): 775-801

Kavussanos M.G., Visvikis I.D. and D. Menachof. 2004. The unbiasedness hypothesis in the Freight Forward Market : Evidence from cointegration tests. Review of Derivatives Research. 7. 241-66 
Koekebakker S. and R.O. Adland. 2004. Modelling forward freight rate dynamics empirical evidence from time charter rates. Maritime Policy and Management. 31(4): $319-35$

Martinez-Garmendia J. and James L. Anderson. 1999. Hedging Performance of shrimp futures contracts with multiple deliverable grades. The Journal of Futures Markets. 19(8): 957-989

Maynard L.J., Hancock S. and H. Hoagland. 2001. Performance of shrimp futures markets as price discovery and hedging mechanisms. Aquaculture Economics and Management. 5(3/4): 115-128

Pennings, J.M. 2002. An European Perspective on Research in Agricultural Futures Markets: Past, Present and Future. Univ. of Illinois, Agricultural \& Cons. Economics Working Paper No. 02-50

Pennings, J.M. and R.M. Leuthold. 2001. Introducing new futures contracts: reinforcement versus cannibalism. Journal of International Money and Finance. 20: $659-75$ 
Reuters. 1999. Introduction to Derivatives. John Wiley and sons

Reuters. 2000, An introduction to the commodities, energy and transport markets, Singapore. John Wiley and Sons

Sanders D.R. and M.R. Manfredo. 2002. The white shrimp futures market: Lessons in contract design and marketing. Agribusiness. 18(4): 505-22

Sanders D.R. and J.M.E. Pennings. 1999. They trade shrimp in Minneapolis? An examination of the MGE white shrimp futures contracts. NCR-134 Conference on Applied Commodity Price Analysis, Forecasting, and Market Risk Management, ed. T.C. Schroeder, pp. 273-88, Dep. Of Ag. Econ., Kansas State University

Stephens John. J. 2000. Managing Commodity Risk: Using Commodity Futures and Options. John Wiley and Sons

Zuniga M., Coble K.H. and R. Heifner. 2001. Evaluation of Hedging in the Presence of Crop Insurance and Government Loan Programs. NCR-134 Conference on Applied 
Commodity Price Analysis, Forecasting, and Market Risk Management. St Louis, Missouri 


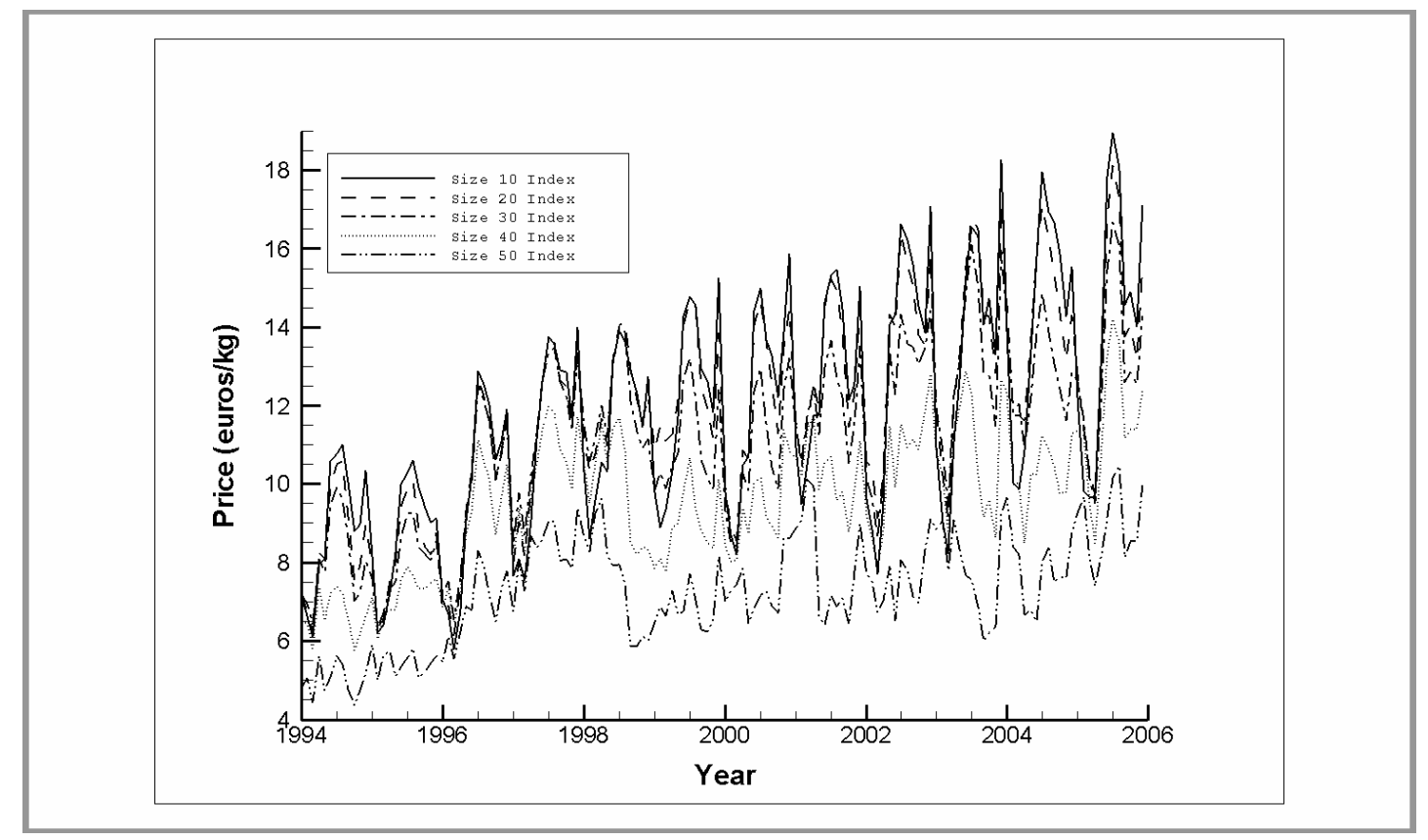

Figure 1. Time series Plot of Indices by Size for Sole

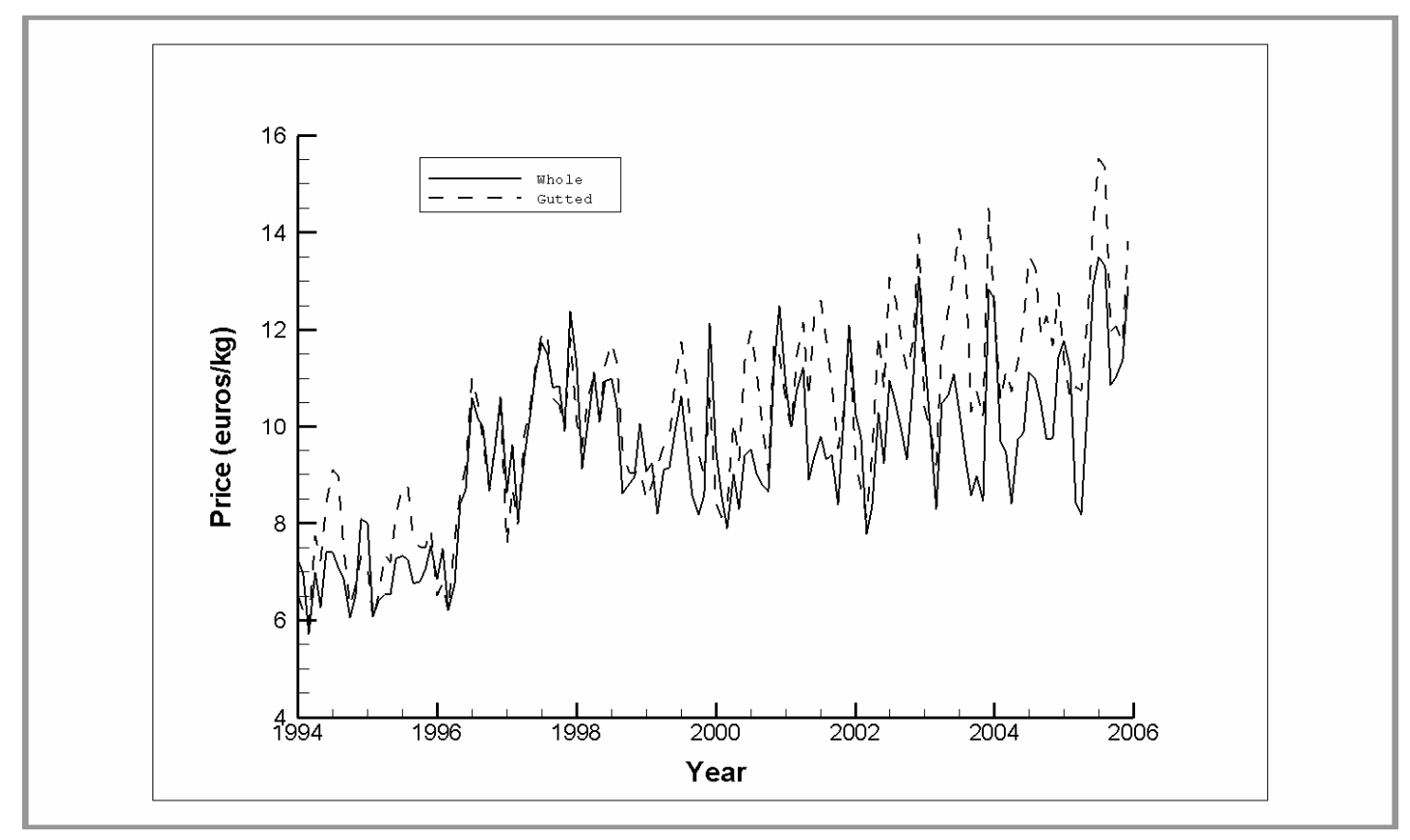

Figure 2. Time series Plot of Indices by Presentations for Sole 


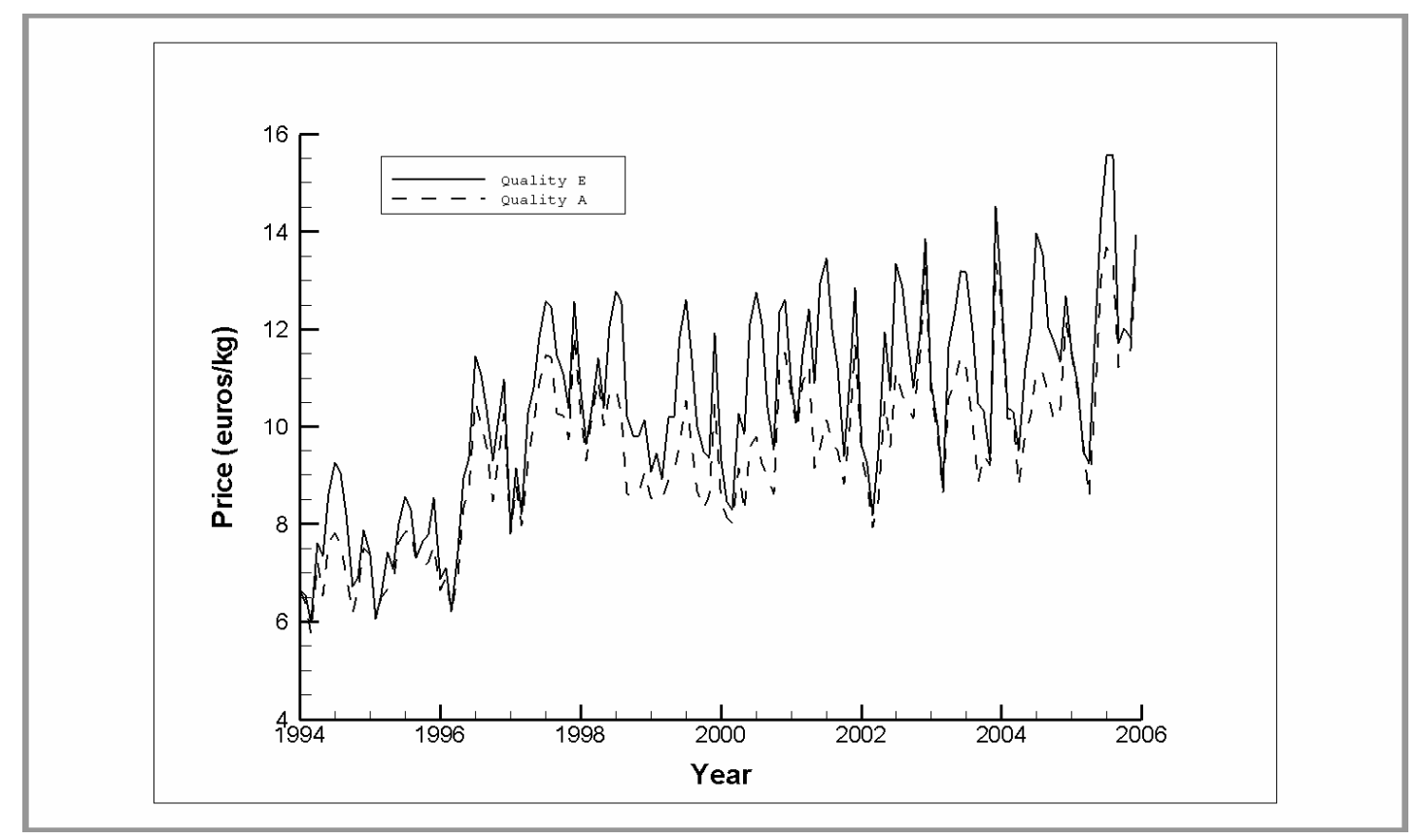

Figure 3. Time series Plot of Indices by Quality for Sole

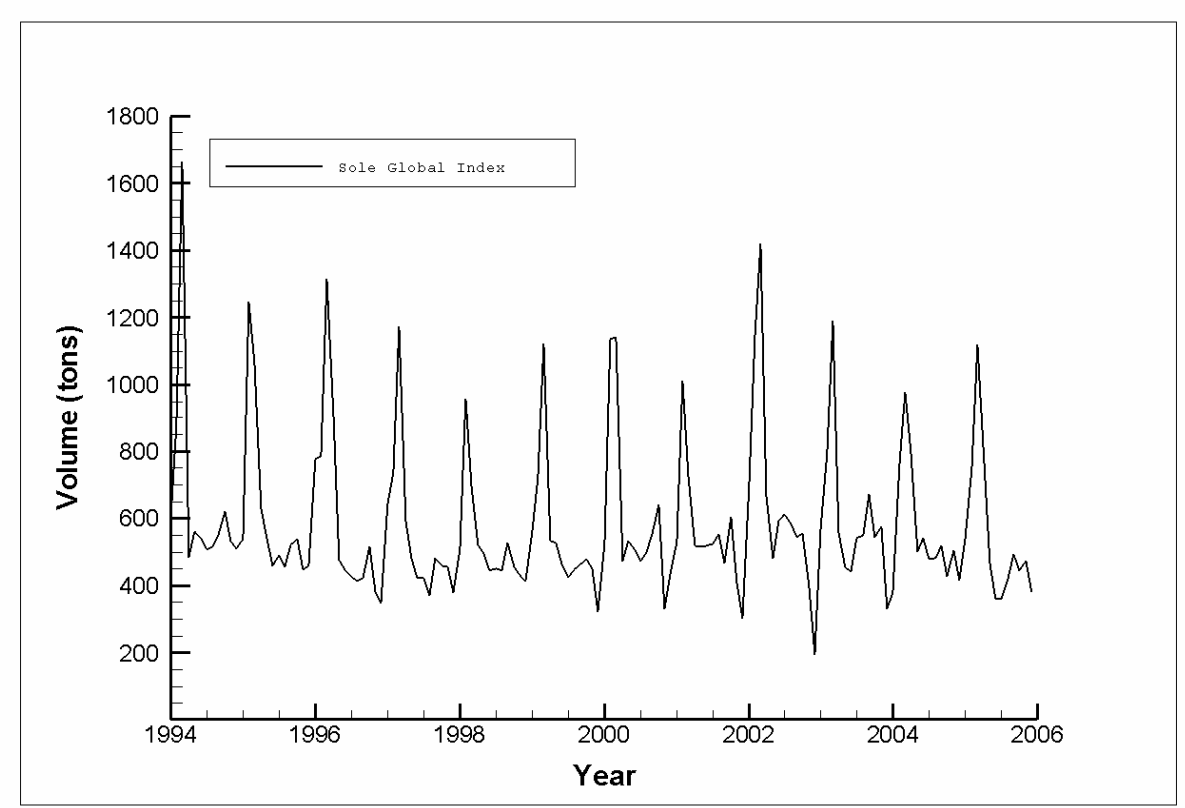

Figure 4. Volume of the Global Index for Sole 


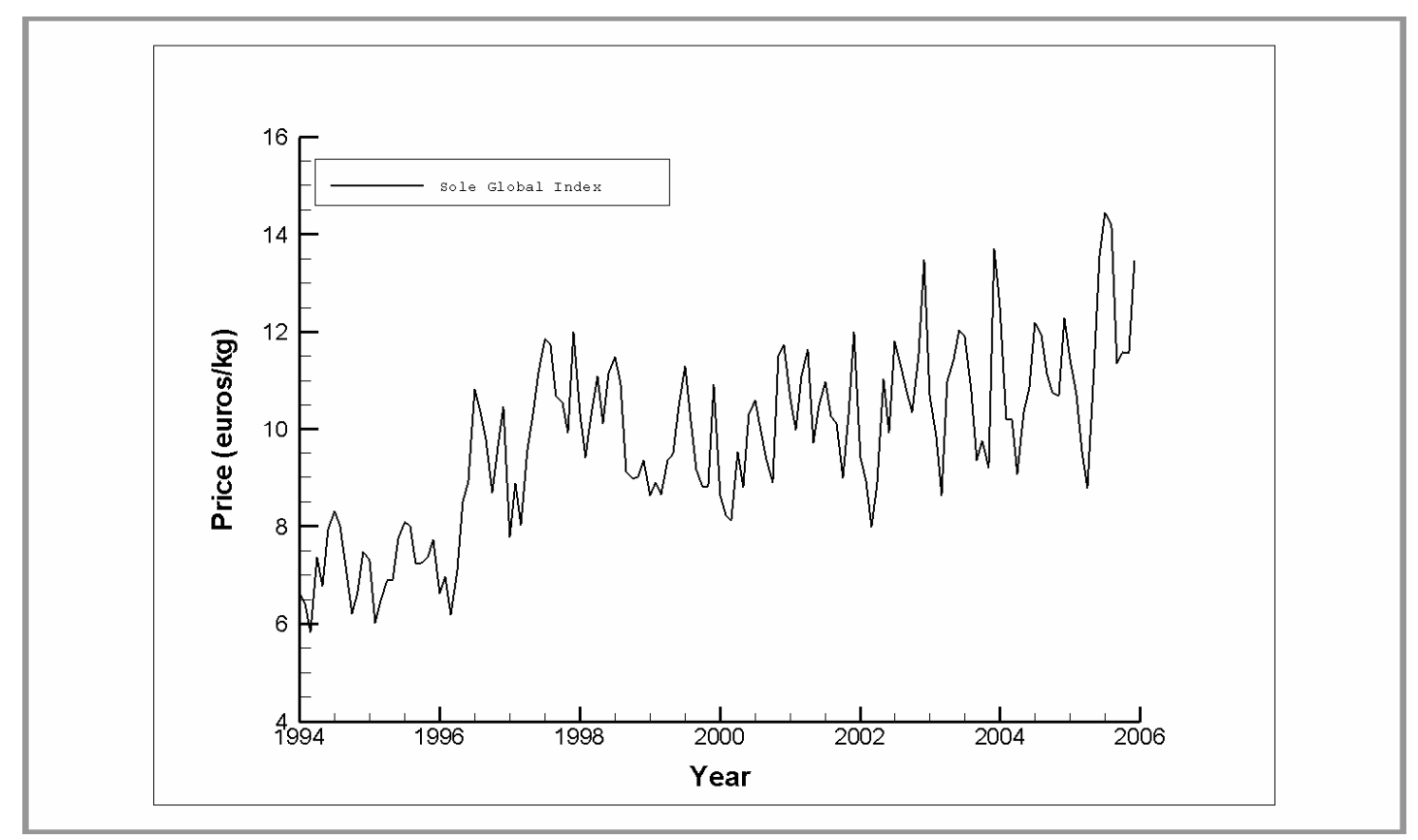

Figure 5. Price dynamics of the Global Index for Sole

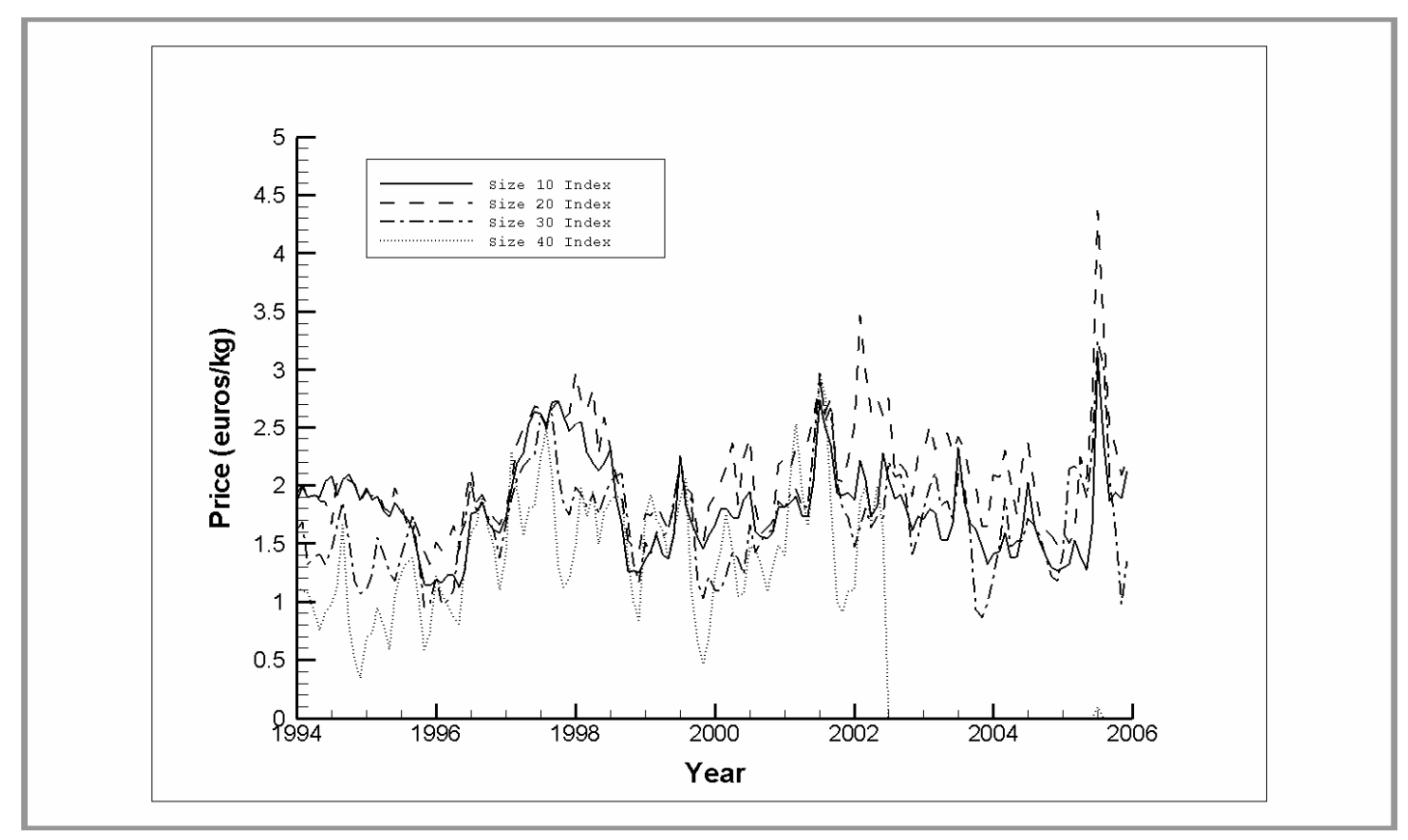

Figure 6. Time series Plot of Indices by Size for Cuttlefish 


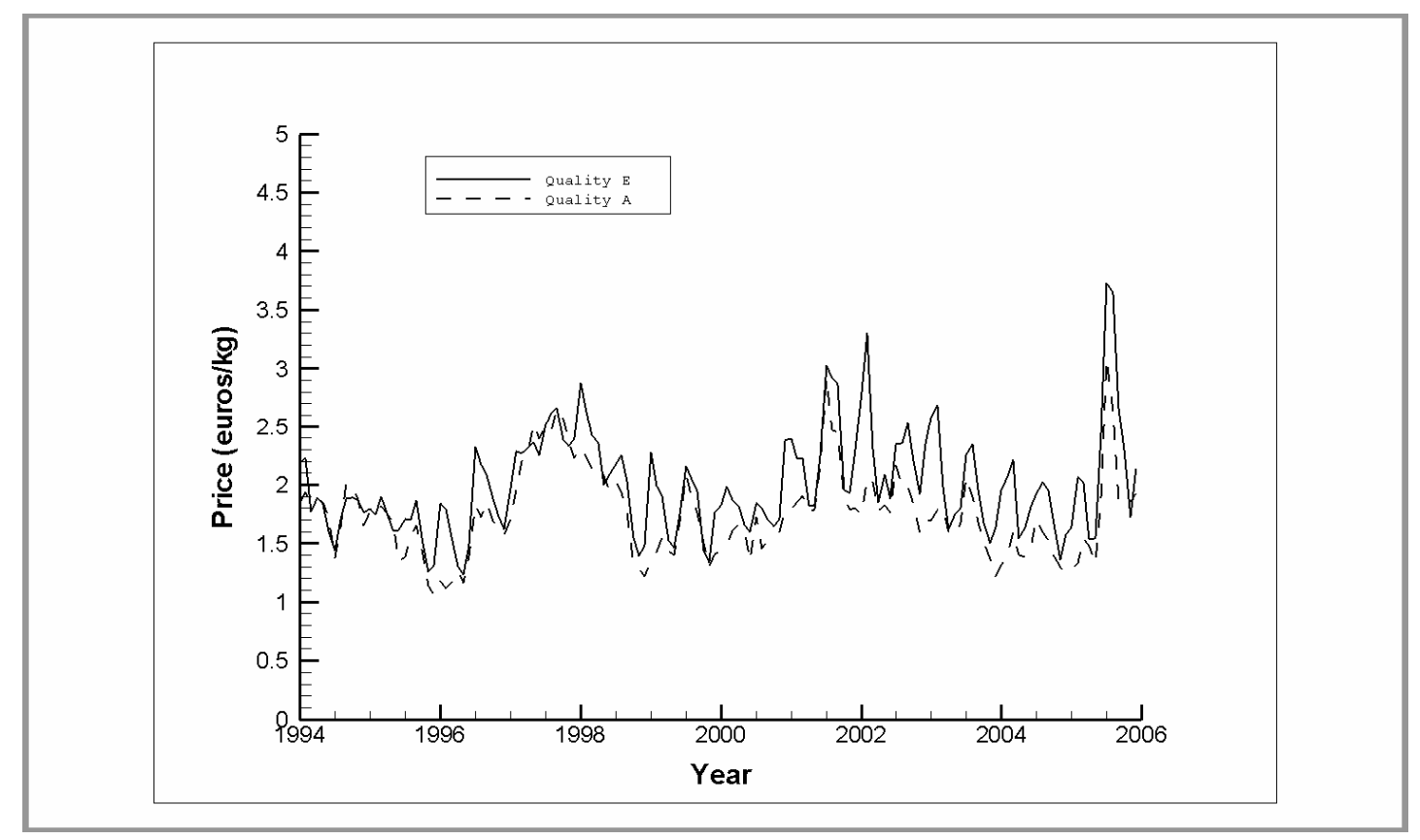

Figure 7. Time series Plot of Indices by Quality for Cuttlefish

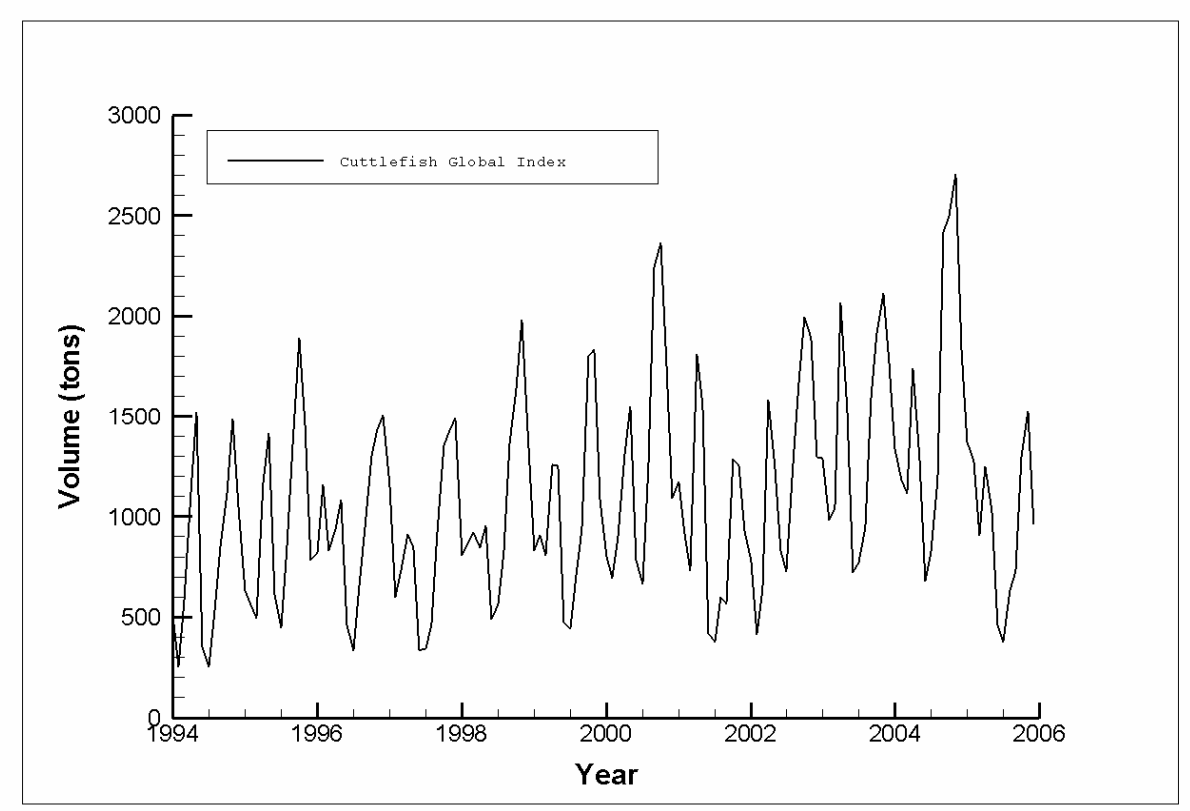

Figure 8. Volume of the Global Index for Cuttlefish 


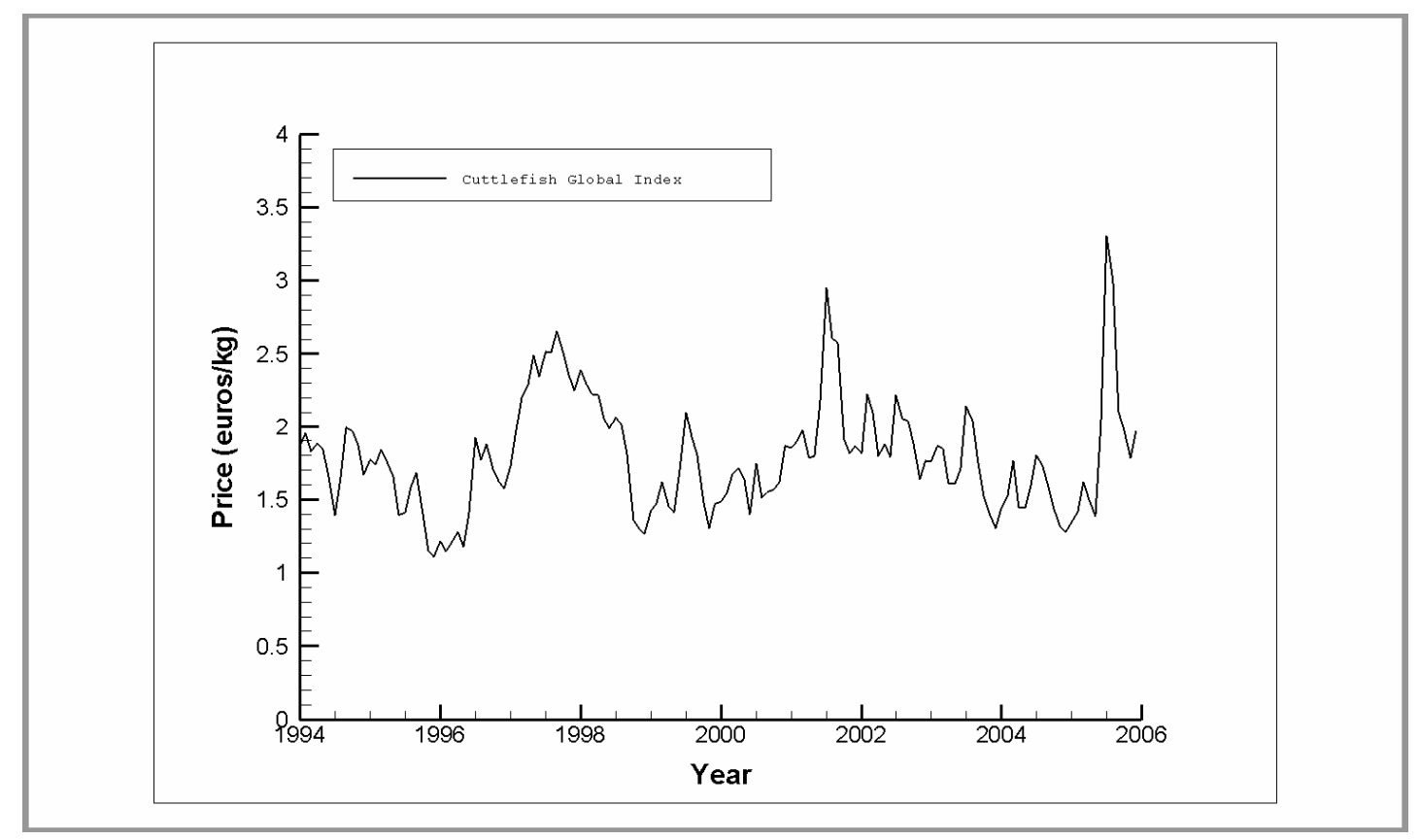

Figure 9. Price dynamics of the Global Index for Cuttlefish 
Table 1

Main Fishing Ports for Sole in France

\begin{tabular}{|c|c|c|c|c|c|}
\hline \multirow[b]{2}{*}{ Fishing Ports } & \multicolumn{2}{|c|}{ Landed quantities (kg) } & \multicolumn{2}{|c|}{ Frequency } & \multirow{2}{*}{$\begin{array}{c}\text { Cumulative } \\
\text { Frequency } 2004\end{array}$} \\
\hline & 1994-2005 & 2004 & $\begin{array}{l}1994- \\
2005\end{array}$ & 2004 & \\
\hline Boulogne & 17082063.3 & 1349205.3 & 19.86 & 19.89 & 19.89 \\
\hline Dunkerque & 5311940.2 & 585718.8 & 6.17 & 8.64 & 28.53 \\
\hline Noirmoutier & 7677045.7 & 505624.2 & 8.92 & 7.46 & 35.98 \\
\hline Arcachon & 5890779.5 & 492170.1 & 6.85 & 7.26 & 43.24 \\
\hline $\begin{array}{l}\text { Les Sables } \\
\text { d'Olonne }\end{array}$ & 8650684.6 & 453881.5 & 10.06 & 6.69 & 49.93 \\
\hline Fécamp & 3060352.5 & 404247.9 & 3.56 & 5.96 & 55.89 \\
\hline Oléron & 5241379.7 & 337922.8 & 6.09 & 4.98 & 60.88 \\
\hline Lorient & 3010616.9 & 306894.7 & 3.50 & 4.53 & 65.40 \\
\hline Ile d'Yeu & 4265177.2 & 196579.9 & 4.96 & 2.90 & 68.30 \\
\hline $\begin{array}{l}\text { Grand-Fort- } \\
\text { Philippe }\end{array}$ & 1288430.3 & 192220.6 & 1.50 & 2.83 & 71.13 \\
\hline Le Croisic & 2623070.4 & 190045.5 & 3.05 & 2.80 & 73.94 \\
\hline Royan & 2778367.4 & 189344.1 & 3.23 & 2.79 & 76.73 \\
\hline
\end{tabular}


Table 2

Distribution by Size of the Production of Sole

\begin{tabular}{ccc}
\hline Size & Description & Frequency \\
\hline 10 & $0.5 \mathrm{~kg}$ and more & 13.39 \\
20 & $0.33-0.5 \mathrm{~kg}$ & 13.87 \\
30 & $0.25-0.33 \mathrm{~kg}$ & 18.99 \\
40 & $200 \mathrm{~g}-250 \mathrm{~g}$ & 30.17 \\
50 & $120 \mathrm{~g}-200 \mathrm{~g}$ & 23.58 \\
\hline
\end{tabular}

Table 3

Correlation Matrix for Sizes of Sole

\begin{tabular}{lccccc}
\hline & Size 10 & Size 20 & Size 30 & Size 40 & Size 50 \\
\hline Size 10 & 1.00 & 0.97 & 0.91 & 0.76 & 0.47 \\
Size 20 & & 1.00 & 0.97 & 0.83 & 0.58 \\
Size 30 & & 1.00 & 0.92 & 0.70 \\
Size 40 & & & 1.00 & 0.88 \\
Size 50 & & & & & 1.00 \\
\hline
\end{tabular}




\section{Table 4}

Main Fishing Ports for Cuttlefish in France

\begin{tabular}{lccccc}
\hline & \multicolumn{2}{c}{ Landed quantities (kg) } & \multicolumn{2}{c}{ Frequency } & Cumulative \\
\cline { 2 - 5 } \multicolumn{1}{c}{ Fishing Ports } & $\mathbf{1 9 9 4 - \mathbf { 2 0 0 5 }}$ & $\mathbf{2 0 0 4}$ & $\mathbf{1 9 9 4 - \mathbf { 2 0 0 5 }}$ & $\mathbf{2 0 0 4}$ & Frequency 2004 \\
\hline Boulogne & 16373709.1 & 2250836.5 & 10.07 & 11.66 & 11.66 \\
Cherbourg & 15175781.4 & 2246886.9 & 9.33 & 11.64 & 23.31 \\
Port en Bessin & 17563816.5 & 1852763 & 10.80 & 9.60 & 32.91 \\
Le Guilvinec & 12888375.9 & 1544121.6 & 7.93 & 8.00 & 40.91 \\
Saint Quay & 8799515.4 & 1325143.2 & 5.41 & 6.87 & 47.78 \\
Portrieux & & & & & \\
Les Sables & 12790259.7 & 1299825.4 & 7.87 & 6.74 & 54.51 \\
d'Olonne & & & & & \\
Erquy & 7651683.8 & 1237866.3 & 4.71 & 6.41 & 60.93 \\
Granville & 12841654.6 & 1215627 & 7.90 & 6.30 & 67.23 \\
Le Croisic & 7182124.4 & 910941.7 & 4.42 & 4.72 & 7.95 \\
La Rochelle & 6397004.1 & 855488.2 & 3.93 & & \\
\hline
\end{tabular}




\section{Table 5}

Distribution by Size of the Production of Cuttlefish

\begin{tabular}{ccc}
\hline Size & Description & Frequency \\
\hline Size 10 & $0.5 \mathrm{~kg}$ and more & 56.31 \\
Size 20 & $0.3-0.5 \mathrm{~kg}$ & 16.06 \\
Size 30 & $0.1-0.3 \mathrm{~kg}$ & 25.24 \\
Size 40 & - & 2.39 \\
\hline
\end{tabular}

\section{Table 6}

Correlation Matrix for Sizes of Cuttlefish

\begin{tabular}{lcccc}
\hline & Size 10 & Size 20 & Size 30 & Size 40 \\
\hline Size 10 & 1.00 & 0.78 & 0.64 & 0.39 \\
Size 20 & & 1.00 & 0.69 & 0.19 \\
Size 30 & & 1.00 & 0.29 \\
Size 40 & & & 1.00 \\
\hline
\end{tabular}




\section{Table 7}

Ten criteria needed for successful derivatives trading

1-Cash Market Size

The size of the market is relatively small compared to the other markets, more specifically agricultural markets for which futures markets were set up.

2- Price Volatility and Price Correlations The volatility seems to be sufficient to perturb all the operators considering the current management of the market or the protections already in place and to require price risk hedging. Price correlation between SPQ criteria is quite high for sole and cuttlefish.

3- Product Homogeneity This is difficult to achieve. The species are very diverse. An index per species seems possible but not a global index. Standardisation will be easier for frozen products than for fresh products. This is facilitated by the standardization of the sales in auction markets (SPQ criteria). 
But most importantly, these operators need to be educated to be able to use these products.

5- Contract Design

Options seem to be preferable to forward and futures. It is the same for an OTC market rather than a regulated market.

6- Price Transparency

It appears to be relatively important for fresh seafood products since the auction system already permits the establishment of a degree of transparency thanks to the existing quotation system.

7- Existing Other Derivative Contracts There is no real problem there as nearly everything remains to be done.

8- Absence of Barriers

This will be a real obstacle to the set up of derivatives markets. The seafood product market is still very much controlled and managed so hedging incentives are limited (Zuniga, Coble and Heifner 2001). However, changes in sales modes, market globalization and current reforms should modify the situation. 
9- Industry Commitment and Floor Trader At first glance, because of its organization Support with fish cooperatives, this sector might be prepared to manage price risk well via a financial instrument market. Nevertheless, it remains to be seen how much commitment the sector will make concerning this subject.

10- Financial Cost This is one of the principal negative aspects. The cost of operating a futures market is high. Even if the sector is already used to some operating principles of the futures markets, the cost may be too high due to the difficulties brought about by the standardization of contracts. Moreover, the costs will be multiplied by the number of indices. Hence an OTC market seems a better solution.

Nota: These are the same criteria than Heifner (2004) 


\section{Footnotes}

1 See the Conference "New commercial and financial data on maritme fishing" University of Nantes, January 1997, Saint-Nazaire.

2 The FPAP was approved by A. Lambert, French Budget Minister, on February 5, 2004. Since this date, $95 \%$ of vessels longer than 12 metres are partially hedged against fuel price risk.

${ }^{3}$ The 10 other species are: angler, scallop shell, pollock, whiting, cod, mackerel, hake, herring, sardine, scampi.

${ }^{4}$ In addition, even supposing the same degree of EU intervention in price support policy, current negotiations concerning EU budgetary perspectives translate into a decrease in financial involvement in favour of the fishing industry.

${ }^{5}$ The second article of the statutes says that "the object of the union is to develop products whose purpose is to permit fishing entrepreneurs to assure the protection from the following risks: fluctuations in the price of diesel oil, maritime pollution or sanitary risks related to pollution, closing of quotas or substantial reduction of fishing possibilities and the relative market risk". 
${ }^{6}$ The system PEFA.COM, which is an acronym for Pan European Fish Auctions, is an electronic commerce tool of the European fish industry.

7 Hull (2005) covers a wide range of derivative products and risk management strategies. Clark, Lesourd and Thieblemont (2001) offer an overview of physical and derivatives commodity markets. Reuters $(1999,2000)$ and Stephens (2000) offer also a good introduction to derivatives and to the management of commodity risk.

${ }^{8}$ More details on these markets can be found in Anderson and Martinez-Garmendia (2003).

${ }^{9}$ To our knowledge, no regulated market of options exists for the fishing industry. The advantages and the disadvantages are the same as for futures markets.

${ }^{10}$ The book by Drewry (2004) provides an extensive survey on these markets and on the risk management tools for shipping.

11 The term "market" is thus a little usurped. One should speak rather of "over the counter transactions on indices". Henceforth we will speak of an index market.

12 Clearing limits the counterpart risk but imposes additional cost and margin calls. Imarex estimates its market share in tanker derivatives overall (Cleared and OTC) of 
around $35 \%$ in 2005 and around $15 \%$ in dry bulk derivatives overall. Drewry (2004) notices that clearing could reach about $40 \%$ of the market activity.

${ }^{13}$ The development of the forward freight market has led nowadays to the application of financial techniques to this market nowadays (see Koekebakker and Adland (2004) with the application of the Heath-Jarrow-Merton model for example).

${ }^{14}$ For example, the indices of size $(10,20,30,40$ and 50) include all the criteria of presentation and quality: the criterion "size" is thus the only element distinctive.

15 The weighting in the index of each auction market from the value of the catch unloaded was also calculated. The differences appear minimal and weighting by volumes was selected.

${ }^{16}$ We do not include in this paper the analysis of the breakdown of the quantities according to criteria of Size, Presentation and Quality, as well as by auction market but it can be found in Bégué-Turon, Perraudeau and Rautureau (2006). This phase enables us, for example, to determine the most significant criteria among the possible existing combinations and to better appreciate the concentration level of the sector. 